\title{
Multiphoton Lithography of Nanocrystalline Platinum and Palladium for Site-Specific Catalysis in 3D Microenvironments
}

\section{Citation}

Zarzar, Lauren D., B. S. Swartzentruber, Jason C. Harper, Darren R. Dunphy, C. Jeffrey Brinker, Joanna Aizenberg, and Bryan Kaehr. 2012. Multiphoton Lithography of Nanocrystalline Platinum and Palladium for Site-Specific Catalysis in 3D Microenvironments. Journal of the American Chemical Society 134, no. 9: 4007-4010. doi:10.1021/ja211602t.

\section{Published Version}

doi:10.1021/ja211602t

\section{Permanent link}

http://nrs.harvard.edu/urn-3:HUL.InstRepos:33204046

\section{Terms of Use}

This article was downloaded from Harvard University's DASH repository, and is made available under the terms and conditions applicable to Open Access Policy Articles, as set forth at http:// nrs.harvard.edu/urn-3:HUL.InstRepos:dash.current.terms-of-use\#OAP

\section{Share Your Story}

The Harvard community has made this article openly available.

Please share how this access benefits you. Submit a story.

Accessibility 


\title{
Multiphoton Lithography of Nanocrystalline Platinum and Palladium for Site-Specific Catalysis in 3D Microenvironments
}

\author{
Lauren D. Zarzar ${ }^{\dagger}$, B. S. Swartzentruber ${ }^{\ddagger}$, Jason C. Harper ${ }^{\S}$ Darren R. Dunphy , C. \\ Jeffrey Brinker§${ }^{\|}$, Joanna Aizenberg ${ }^{\perp^{{ }_{\#}} *}$, and Bryan Kaehr ${ }^{\S} \|_{*}$ \\ ${ }^{\dagger}$ Department of Chemistry and Chemical Biology, Harvard University, Cambridge, Massachusetts 02138, \\ United States \\ ${ }^{\ddagger}$ Center for Integrated Nanotechnologies, Sandia National Laboratories, Albuquerque, New Mexico \\ 87106, United States \\ §Department of Chemical and Nuclear Engineering and Center for Micro-Engineered Materials, \\ University of New Mexico, Albuquerque, New Mexico 87206, United States \\ "Advanced Materials Laboratory, Sandia National Laboratories, Albuquerque, New Mexico 87106, United \\ States \\ ${ }^{\perp}$ School of Engineering and Applied Sciences, Harvard University, Cambridge, Massachusetts 02138, \\ United States \\ \#Wyss Institute for Biologically Inspired Engineering, Harvard University, Cambridge, Massachusetts \\ 02138, United States
}

Supporting Information Placeholder

\begin{abstract}
Integration of catalytic nanostructured platinum and palladium within $3 \mathrm{D}$ microscale structures or fluidic environments is important for systems ranging from micropumps to microfluidic chemical reactors and energy converters. We report a generalizable and straightforward route to fabricate microscale patterns of nanocrystalline platinum and palladium using multiphoton lithography (MPL). These materials display excellent catalytic, electrical, and electrochemical properties and we demonstrate high resolution integration of catalysts within $3 \mathrm{D}$-defined microenvironments to generate directed autonomous particle and fluid transport.
\end{abstract}

Platinum and palladium catalysts are crucial for a broad range of existing and emerging chemical, biological, and technological applications and so consequently, substantial recent work has been aimed at understanding and improving their function and efficiency and reducing their consumption/utilization via nanostructuring. ${ }^{1}$ Despite progress towards directed synthesis of a wide variety of platinum and palladium nanostructures and alloys, there are few reported strategies for integration of these catalysts within nano or micro-scale platforms. Specifically, abilities to dictate catalysis within microfluidic systems are crucial for the success of lab on chip devices which rely on well-defined catalyst/substrate interactions for improved efficiency, portability, and cost. ${ }^{2}$ Increasingly microfluidic designs incorporate $3 \mathrm{D}$ channel geometries 3,4 and therefore development of a strategy for precise positioning of catalysts within $3 \mathrm{D}$ microfluidics should prove enabling for a wide range of technologies including autonomously powered microfluidics, diagnostics, microreactors, and sensors as well as energy generation, conversion, and storage applications..$^{-7}$

Platinum, palladium and rhodium have been incorporated into a microfluidic hydrogenation reactors via processes such as sputtering, $, 8,9$ and recently $\mathrm{Xu}$ et al. used direct laser writing to pattern catalytic and SERS active silver microflowers within a microfluidic channel. ${ }^{10}$ Despite these examples, the scope of catalyst printing for microreactors remains limited and successful integration of catalysts such as Pt and Pd within 3D microfluidics has not been demonstrated.

Here we describe a straightforward procedure to integrate arbitrary micropatterns of nanostructured $\mathrm{Pt}$ and $\mathrm{Pd}$ within $3 \mathrm{D}$ fluidic architectures using multiphoton lithography (MPL), an intrinsically $3 \mathrm{D}$ direct-write technique. ${ }^{11,12}$ These MPL-deposited Pt and Pd materials are composed of polycrystalline metallic nanoparticles that show excellent electronic, electrochemical, and catalytic properties. We show that site-specific $\mathrm{H}_{2} \mathrm{O}_{2}$ decomposition catalyzed by MPL-directed Pt can be used to drive directed fluid flow in three dimensions upon integration within appropriately designed $3 \mathrm{D}$ structural 
(a)

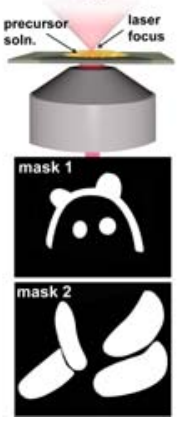

(b)

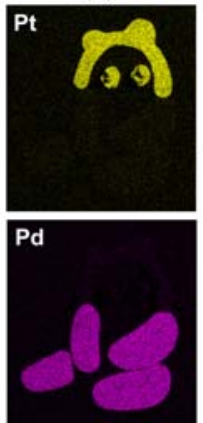

(c)

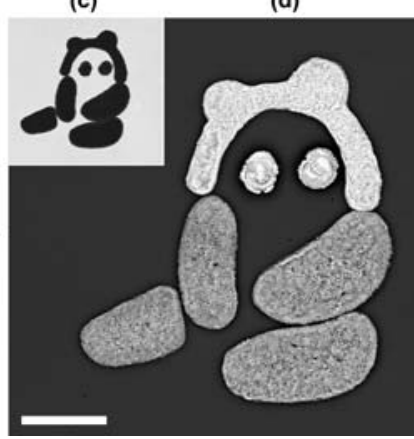

Figure 1. (a) Fabrication schematic showing the two digital masks used to define Pt and Pd. (b) EDS image maps indicating regions of $\mathrm{Pt}$ and $\mathrm{Pd}$. (c) Bright field optical micrograph. (d) Backscatter SEM. Scale bar, $20 \mu \mathrm{m}$.

components which we envision can be applied broadly for site specific catalysis in microfluidic environments, for instance, toward the design and testing of catalytic micro-pumps and motors. 13-17

The use of MPL to form conductive metallic structures has been explored, ${ }^{18-21}$ however, reports on MPL of catalytic materials are scant ${ }^{10,22}$ and the use of MPL to form Pt and Pd materials has not been reported. Previously, photoreduced Pt and Pd nanomaterials have been synthesized using methods often requiring the use of chemical stabilizers in order to generate nanoparticles or nanowires ${ }^{23-26}$. To adapt the synthesis of Pd and Pt nanocrystals for MPL conditions, we explored the use of precursors often used in platinotype/palladiotype photographic processes first developed in the late $19^{\text {th }}$ century 27 and recently adapted by Jiang and Miller for fuel cell applications. ${ }^{28,29}$ In one such printing method, paper (serving as the support matrix) is embedded with $\left(\mathrm{NH}_{4}\right)_{2}\left[\mathrm{PtCl}_{4}\right]$, or $\left(\mathrm{NH}_{4}\right)_{2}\left[\mathrm{PdCl}_{4}\right]$ and $\left(\mathrm{NH}_{4}\right)_{3}\left[\mathrm{Fe}\left(\mathrm{C}_{2} \mathrm{O}_{4}\right)_{3}\right]$ and exposed to UV light inducing photochemical reduction of the iron to form a strong reducing agent which can then reduce, for instance, Pt(II) to Pt(o) following the reactions:

$\left.\mathrm{hv}+2\left[\mathrm{Fe}\left(\mathrm{C}_{2} \mathrm{O}_{4}\right)_{3}\right]^{3-} \rightarrow \mathrm{Fe}\left(\mathrm{C}_{2} \mathrm{O}_{4}\right)_{2}\right]^{2-}+\mathrm{C}_{2} \mathrm{O}_{4}{ }^{2-}+2 \mathrm{CO}_{2}$

$\left[\mathrm{PtCl}_{4}\right]^{2-}+2\left[\mathrm{Fe}\left(\mathrm{C}_{2} \mathrm{O}_{4}\right)_{2}\right]^{2-} \rightarrow \mathrm{Pt} \downarrow+2\left[\mathrm{Fe}\left(\mathrm{C}_{2} \mathrm{O}_{4}\right)_{2}\right]^{-}+4 \mathrm{Cl}^{-}$

To investigate MPL of Pt and Pd by adapting this photographic process, we mixed a 1:1 precursor solution comprised of $0.7 \mathrm{M}$ of either the $\left(\mathrm{NH}_{4}\right)_{2}\left[\mathrm{PtCl}_{4}\right]$, or the $\left(\mathrm{NH}_{4}\right)_{2}\left[\mathrm{PdCl}_{4}\right]$ and $1.0 \mathrm{M}$ of the iron (III) oxalate and tested $\mathrm{Pt} / \mathrm{Pd}$ direct-writing using a mode-locked Titanium: Sapphire laser centered at $750 \mathrm{~nm}$ and focused upon a glass cover slip (Supporting Information). Using this procedure, Pt and Pd patterns could be printed sequentially on un-modified glass with arbitrary shapes and intrinsic registration using a scanning laser, dynamic-mask based approach (Figure 1a). ${ }^{12}$ Bubbles were observed emanating from the opaque structure at the point of laser focus/fabrication, indicating solution boiling with likely contribution of evolution of $\mathrm{CO}_{2}$ from ferric oxalate reduction (Supporting Movie 1). Structures could be rinsed rigorously post-fabrication without any detectible delamination or degradation. Panels (b) and (d) of Figure 1 show energy-dispersive X-ray spectrographs (EDS) and backscatter scanning electron micrographs
(SEM) respectively demonstrating the fabrication of well defined patterns of highly pure (i.e., no iron oxide contaminant detected with EDS) Pt and Pd.

The $\quad\left(\mathrm{NH}_{4}\right)_{2}\left[\mathrm{PtCl}_{4}\right], \quad\left(\mathrm{NH}_{4}\right)_{2}\left[\mathrm{PdCl}_{4}\right]$ and $\left(\mathrm{NH}_{4}\right)_{3}\left[\mathrm{Fe}\left(\mathrm{C}_{2} \mathrm{O}_{4}\right)_{3}\right]$ precursors display no significant absorbance above $\sim 550 \mathrm{~nm}$ (Figure $\mathrm{S} 1$ ), ${ }^{27}$ and excitation of the charge-transfer band of $\left[\mathrm{Fe}\left(\mathrm{C}_{2} \mathrm{O}_{4}\right)_{3}\right]^{3-}$, which is required for its subsequent photolysis, is achieved in the range of $\sim 200-500 \mathrm{~nm} .{ }^{30,31}$ Thus, as expected, no initial deposition was observed when $5 \mathrm{~mW}$ continuous wave (CW) $750 \mathrm{~nm}$ light was employed. High resolution SEMs (Figure 2) show that the metallic patterns are comprised of small metallic granules, indicating that the rate of photoreduction within the focal volume is limited by the diffusion of metallic precursors. ${ }^{22-34}$ SEM cross-sectional analysis of an exemplary Pd structure revealed that the granular surface, in large part, is continuous throughout the structure interior down to the glass/metal interface at which point the structure appears solidified, indicating thermal melting/annealing at the interface-a consequence of heating via light absorption by the metallic pads. We estimated the steady state temperature rise $(\Delta \mathrm{T})$ at the laser focal point of the glass/metal interface using the solution for the low frequency limit (essentially CW) of the laser modulation: 35

$$
\Delta \mathrm{T}=\frac{A_{0}}{2 \sqrt{\pi} \omega_{0} \Lambda}
$$

where $\mathrm{A}_{0}$ is the average power $(\sim 5 \mathrm{~mW})$ multiplied by the percentage of light absorbed by the metal at 750 $\mathrm{nm}(\sim 30 \%$ for $\mathrm{Pt}$ and $\mathrm{Pd}), \mathrm{w}_{\mathrm{o}}$ is the $1 / \mathrm{e}^{2}$ radius of the focused laser spot $(\sim 350 \mathrm{~nm})$, and $\Lambda$ is the thermal conductivity of the glass $\left(1.3 \mathrm{Wm}^{-1} \mathrm{~K}^{-1}\right)$ giving a maximum
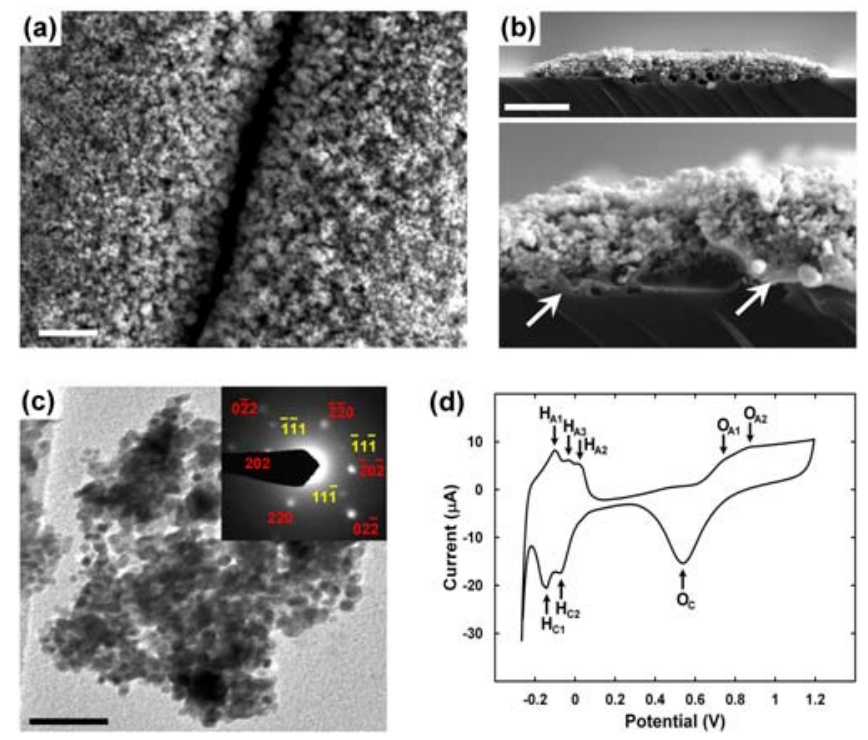

Figure 2. (a) Two Pd structures separated by a $\sim 200 \mathrm{~nm}$ gap. Scale bar, $1 \mu \mathrm{m}$. (b) Cross section of a MPL-Pd line showing melting/annealing of the glass (left arrow) and Pd (right arrow). Scale bar, $5 \mu \mathrm{m}$. (c) TEM of MPL-Pt crystallites and electron diffraction pattern obtained from the edge of a cluster (corresponding to two crystallites). Scale bar, $50 \mathrm{~nm}$. (d) CV of an MPL-Pt working electrode in 1.o $\mathrm{M} \mathrm{H}_{2} \mathrm{SO}_{4}$ shows hydrogen adsorption (cathodic peaks; $\mathrm{H}_{\mathrm{C}}$ ) and desorption (anodic peaks; $\mathrm{H}_{\mathrm{A}}$ ) and formation $\left(\mathrm{O}_{\mathrm{A} 1,2}\right)$ and subsequent reduction $\left(\mathrm{O}_{\mathrm{C}}\right)$ of an oxide layer. 
steady state temperature rise of $\sim 930 \mathrm{~K}$ under these conditions which is substantially higher than the annealing point for borosilicate cover glass $\left(557^{\circ} \mathrm{C}\right) .3^{36}$ Interestingly, we observed that further deposition of chemically and structurally identical Pt or Pd could be extended from an existing metallic structure using 750 nm CW laser light and the same precursor solutions; structures could not be deposited in this manner in the absence of the iron sensitizer. These observations indicate that the heat generated at the point of focus at the glass/metal interface leads to localized thermal decomposition/reduction of the ferric oxalate into an iron (II) reducing agent. The mechanism of metal oxalate thermal decomposition and resulting intermediates is highly dependent on experimental and environmental conditions 37 but extensive heating can result in the reduction of iron (III) to iron (II) with $\mathrm{FeC}_{2} \mathrm{O}_{4}$ as a possible intermediate..$^{8} \mathrm{FeC}_{2} \mathrm{O}_{4}$ has also been shown to reduce platinum and palladium precursors salts. ${ }^{27}$ Moreover, this mechanism provides an avenue to explore direct-writing of metals using widely available and less costly CW light sources.

Using our direct write set-up, we observed a reproducible minimum line width of ca. $2 \mu \mathrm{m}$, with gap width resolutions of ca. $200 \mathrm{~nm}$ (Figure 2a). $39 \mathrm{We}$ characterized the electrical properties of MPL-Pt and Pd lines written on glass substrates using an in situ nanoprobe technique (Supporting Information) and measured resistivity values of $4.2 \pm 0.5$ and $2.3 \pm 0.3$ $(\mu \Omega \cdot \mathrm{m})$ for Pt and Pd respectively which is approximately one order of magnitude higher than those for bulk metals. Further characterization of the crystallinity and electrochemical properties of MPL-Pt was carried out using transmission electron microscopy (TEM). TEM analysis of the MPL-deposited Pt scraped from glass substrates showed clusters with crystallites ranging in diameter from $4-8 \mathrm{~nm}$ (Figure 2c), and distinct crystallographic planes could be resolved in the electron diffraction pattern of crystallites located at cluster edges (Figure 2c inset). Cyclic voltammetry (CV) was used to characterize MPL-Pt (Figure 2 and Supporting Information) and we measured an electroactive surface area to geometric surface area ratio of $\sim 36$.

The emerging field of synthetic catalytic nanomotors and pumps provides an exciting testbed to explore nanomaterials with life-like energy conversion strategies.5-7,40 To achieve the work necessary to directionally power such devices generally requires asymmetric placement of the catalyst in relation to the surrounding environment in order to generate net directional motion and flow. ${ }^{16,17,41}$ MPL enables arbitrary $3 \mathrm{D}$ structures to be readily designed and fabricated allowing functional/asymmetric geometries to be rapidly prototyped. We explored Pt catalyzed decomposition of hydrogen peroxide to generate directed fluid and particulate flow within 3D micro-chambers and channels. In Figure 3a, a Pt pad was patterned onto glass and then encased within a photo-crosslinked protein chamber containing a self-crossing spiral outlet. Addition of $1 \% \mathrm{H}_{2} \mathrm{O}_{2}$ resulted in continuous and directed flow of oxygen through the spiral (Supporting Movie 2) as the peroxide substrate could be replenished at the catalytic site, for the most part, via diffusion across the protein hydrogel chamber walls and ceiling thereby allowing the majority of the spiral channel to maintain constant $\mathrm{O}_{2}$ pressure. In contrast, directing the oxygen outflow into an asymmetric channel (Figure $3 \mathrm{~b}$ ) resulted in a peristalsis-like effect on the channel, with the channel fluid periodically compressed and released by the oxygen bubble evolution and resultant negative pressure developed upon outflow. Pumping is illustrated by the directional transport of microspheres at relatively high velocities (up to ca. $60 \mu \mathrm{m} \mathrm{s}^{-1}$ ) through the channel (Figure 3b and Supporting Movie 3). Importantly, this approach offers greater flexibility versus existing techniques 15,17 in the design of autonomously powered microfluidics.

Finally, we explored Pt patterning within a preformed $3 \mathrm{D}$ microenvironment. Unfortunately, formation of metallic pads on protein substrates resulted in deformation of the protein support. However, this challenge was overcome by developing a silica composite ${ }^{42}$ which provided sufficient mechanical reinforcement of the structural surfaces defined by the protein template to withstand the subsequent heat generated during metal deposition. We designed a geometry where gas flow is forced downward, underneath the catalyst, to exit into the surrounding fluid (Figure 3c). Traversing the imaging plane through the structure shows that the gas generated from the top chamber is directed underneath the $\mathrm{Pt}$ catalyst (Supporting Movie 4), demonstrating high resolution integration of a metallic component that is otherwise unachievable without $3 \mathrm{D}$ lithographic control.

We have demonstrated that MPL of Pt and Pd facilitates the design of dynamic microsystems based on harnessing localized catalysis within ${ }_{3} \mathrm{D}$
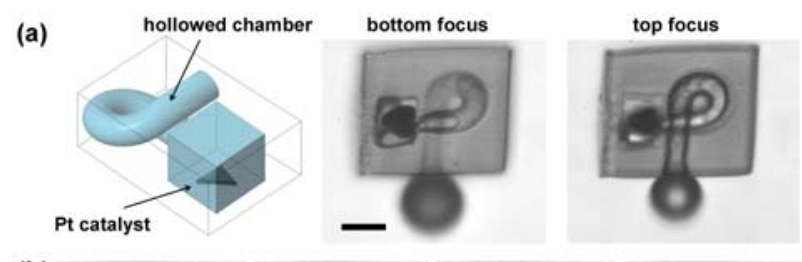

(b)

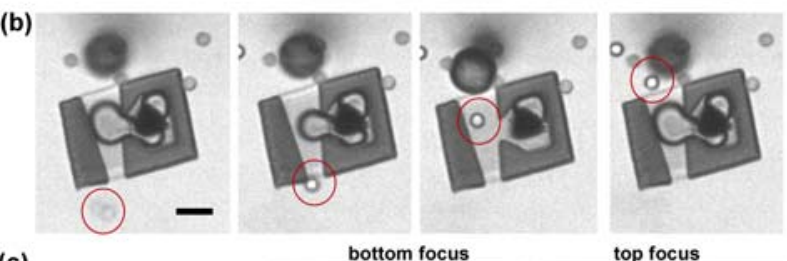

(c)

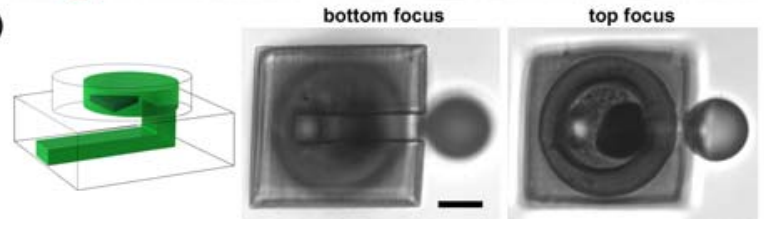

Figure 3. (a) A Pt catalyst contained in a protein chamber directs gas through a self-crossing spiral channel. (b) The directional outflow of gas produced at an MPL-Pt catalyst contained in a microchamber pumps a $5 \mu \mathrm{m}$ particle (circled in red) through the asymmetric channel over approximately 1 second. (c) An MPL-Pt catalyst printed inside the upper chamber of a $3 \mathrm{D}$ microchamber directs gas flow downwards underneath the catalvst. Scale bars, 10 um. 
microenvironments to generate directed fluid and gas flow. These autonomous pumps and fluidics may be useful for flow generation, fluid mixing, propulsion, collection and transport. Additionally MPL-Pt and Pd materials display excellent electronic and catalytic functionality; further enhancement is expected by exploring alloyed systems and controlling resolution and particle morphology using structure-directing agents,1,32,43,44 or electroplating techniques.34 Fabrication of Pt and Pd structures with free-form, 3D architectures is currently being investigated through judicial variation of the chemical and environmental parameters in an effort to overcome the low structure fidelity incurred via laser heating. ${ }^{18,19,32}$ The ability to prototype arbitrary $3 \mathrm{D}$ microscale electroactive and catalytic surfaces provides a new toolset with which to fabricate dynamic, $3 \mathrm{D}$ nano/microscale systems.

\section{ASSOCIATED CONTENT}

Experimental protocols, resistivity and electrochemical analysis are provided in the Supporting Information. This material is available free of charge via the Internet at http://pubs.acs.org.

\section{AUTHOR INFORMATION}

\section{Corresponding Authors}

*jaiz@seas.harvard.edu, *bjkaehr@sandia.gov

\section{ACKNOWLEDGMENT}

We acknowledge support from U.S. Department of Energy (DOE), Office of Science, Office of Basic Energy Sciences (BES), Division of Materials Sciences and Engineering. Work was performed, in part, at CINT, a U.S. DOE, BES user facility. L.D.Z. thanks the DOD-NDSEG, the NSF-GRF and the NINE program at Sandia for support. Sandia National Laboratories is a multi-program laboratory managed and operated by Sandia Corporation, a wholly owned subsidiary of Lockheed Martin Corporation, for the U.S. Department of Energy's National Nuclear Security Administration under contract DE-AC04-94AL85000.

\section{REFERENCES}

(1) Chen, A.; Holt-Hindle, P. Chem. Rev. 2010, 110, 3767.

(2) Mark, D.; Haeberle, S.; Roth, G.; Von Stetten, F.;

Zengerle, R. Chem. Soc. Rev. 2010, 39, 1153.

(3)Liao, Y.; Song, J.; Li, E.; Luo, Y.; Shen, Y.; Chen, D.; Cheng, Y.; Xu, Z.; Sugioka, K.; Midorikawa, K. Lab Chip 2012, 12, 746.

(4)Ke, K.; Hasselbrink Jr, E. F.; Hunt, A. J. Anal. Chem. 2005, 77, 5083 .

(5)Paxton, W. F.; Sundararajan, S.; Mallouk, T. E.; Sen, A. Angew. Chem. Int. Edit. 2006, 45, 5420.

(6) Wang, J. ACS Nano 2009, 3, 4.

(7) Mei, Y.; Solovev, A. A.; Sanchez, S.; Schmidt, O. G. Chem. Soc. Rev. 2011, 40, 2109.

(8) Iles, A.; Habgood, M.; de Mello, A. J.; Wootton, R. C. R. Catal. Lett. 2007, 114, 71.

(9) Urakawa, A.; Trachsel, F.; von Rohr, P. R.; Baiker, A. Analyst 2008, 133, 1352.

(10) Xu, B.-B.; Zhang, R.; Liu, X.-Q.; Wang, H.; Zhang, Y.L.; Jiang, H.-B.; Wang, L.; Ma, Z.-C.; Ku, J.-F.; Xiao, F.-S.; Sun, H.-B. Chem. Commun. 2012, 48, 1680

(11) Kaehr, B.; Shear, J. B. J. Am. Chem. Soc. 2007, 129,
(12) Nielson, R.; Kaehr, B.; Shear, J. B. Small 2009, 5, 120.

(13) Ismagilov, R. F.; Schwartz, A.; Bowden, N.; Whitesides, G. M. Angew. Chem. 2002, 114, 674.

(14) Paxton, W. F.; Kistler, K. C.; Olmeda, C. C.; Sen, A.; Angelo, S. K. S.; Cao, Y.; Mallouk, T. E.; Lammert, P. E.; Crespi, V. H. J. Am. Chem. Soc. 2004, 126, 13424.

(15) Kline, T. R.; Paxton, W. F.; Wang, Y.; Velegol, D.; Mallouk, T. E.; Sen, A. J . Am. Chem. Soc. 2005, 127, 17150.

(16) Solovev, A. A.; Mei, Y.; Ureña, E. B; Huang, G.; Schmidt, O. G. Small 2009, 5, 1688.

(17) Solovev, A. A.; Sanchez, S.; Meiz, Y.; Schmidt, O. G. Phys. Chem. Chem. Phys. 2011, 13, 10131.

(18) Tanaka, T.; Ishikawa, A.; Kawata, S. Appl. Phys. Lett. 2006, 88, o81107.

(19) Ishikawa, A.; Tanaka, T.; Kawata, S. Appl. Phys. Lett. 2006, 89, 113102.

(20) Xu, B.-B.; Xia, H.; Niu, L.-G.; Zhang, Y.-L.; Sun, K.; Chen, Q.-D.; Xu, Y.; Lv, Z.-Q.; Li, Z.-H.; Misawa, H.; Sun, H.-B. Small 2010, 6, 1762.

(21) Maruo, S.; Saeki, T. Optics Express 2008, 16, 1174.

(22) Allen, R.; Nielson, R.; Wise, D. D.; Shear, J. B. Anal. Chem. 2005, 77, 5089.

(23) Einaga, H.; Harada, M. Langmuir 2005, 21, 2578.

(24) Bai, L.; Zhu, H.; Thrasher, J. S.; Street, S. C. ACS Appl. Mater. Interfaces 2009, 1, 2304.

(25) Harada, M.; Saijo, K.; Sakamoto, N. Colloids Surface A 2009, 349, 176 .

(26) Sakamoto, Y.; Fukuoka, A.; Higuchi, T.; Shimomura, N.; Inagaki, S.; Ichikawa, M. J . Phys. Chem. B. 2004, 108, 853.

(27) Ware, M. J. Photogr. Sci. 1986, 34, 165.

(28) Jiang, J.; Hall, T. D.; Tsagalas, L.; Hill, D. A.; Miller, A. E. J . Power Sources 2006, 162, 977.

(29) Redjala, T.; Apostolecu, G.; Beaunier, P.; Mostafavi, M.; Etcheberry, A.; Uzio, D.; Thomazeaud, C. c.; Remita, H. New J. Chem. 2008, 32, 1403.

(30) Porter, G. B.; Doering, J. G. W.; Karanka, S. J. Am. Chem. Soc. 1962, 84, 4027.

(31) Chen, J.; Zhang, H.; Tomov, I. V.; Rentzepis, P. M. Inorg. Chem. 2008, 47, 2024.

(32) Cao, Y.-Y.; Takeyasu, N.; Tanaka, T.; Duan, X.-M.; Kawata, S. Small 2009, 5, 1144. 1426.

(33) Kaneko, K.; Sun, H.-B. Appl. Phys. Lett. 2003, 83,

(34) LaFratta, C. N.; Fourkas, J. T.; Baldacchini, T.; Farrer, R. A. Angew. Chem. Int. Ed. 2007, 46, 6238.

(35) Cahill, D. G. Rev. Sci. Instrum. 2004, 75, 5119.

(36) Ted Pella, Inc., http://tedpella.com/, (accessed Nov 1, 2011).

(37) Dollimore, D. Thermochim. Acta 1987, 117, 331.

(38) Gallagher, P. K.; Kurkjian, C. R. Inorg. Chem. 1966, $5,214$.

(39) The discrepancy between minimum line width and laser spot size $(\sim 700 \mathrm{~nm})$ is attributed to heating at the laser focal point, as discussed, which degrades resolution by increasing the size of the effective volume where precursors are reduced.

(40) Paxton, W. F.; Baker, P. T.; Kline, T. R.; Wang, Y.; Mallouk, T. E.; Sen, A. J . Am. Chem. Soc. 2006, 128, 14881. 5268 .

(41) Kaehr, B.; Brinker, C. J. Chem. Comm. 2010, 46,

(42) Khripin, C. Y.; Pristinski, D.; Dunphy, D. R.; Brinker, C. J.; Kaehr, B. ACS Nano 2011, 5, 1401.

(43) Zhang, Y.-L.; Chen, Q.-D.; Xia, H.; Sun, H.-B. Nano Today 2010, 5, 435 .

(44) Cao, Y.-Y.; Dong, X.-Z.; Takeyasu, N.; Tanaka, T.; Zhao, Z.-S.; Duan, X.-M.; Kawata, S. Appl. Phys. A 2009, 96, 453. 1904. 


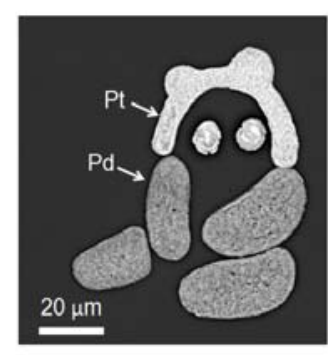

